\title{
The Acute Frailty Network: experiences from a whole-systems quality improvement collaborative for acutely ill older patients in the English NHS
}

\author{
James David van Oppen ${ }^{1}\left[\right.$ ] Deborah Thompson ${ }^{2} \cdot$ Matt Tite $^{2} \cdot$ Simon Griffiths ${ }^{2} \cdot$ Finbarr C. Martin ${ }^{2,3}$. \\ Simon Conroy ${ }^{1,2}$ (1)
}

Received: 1 December 2018 / Accepted: 22 February 2019 / Published online: 7 March 2019

(c) European Geriatric Medicine Society 2019

\section{Key summary points}

Aim To describe the approach and methods of the Acute Frailty Network.

Findings Local case studies are used to illustrate the early impact of the Network. Reflections on three years' experience of planning and implementing a whole-systems quality improvement collaborative are shared.

Message Initiatives through which hospitals improved services and outcomes for older people with frailty and urgent care needs are illustrated.

\begin{abstract}
Older people form a growing proportion and volume of those accessing urgent care, much of which is provided by nonspecialists in geriatric medicine. Non-specific presentations, multiple comorbidities and functional decline make assessment and management of this cohort challenging. In this article we describe the approach and methods of the Acute Frailty Network (AFN), a national quality improvement collaborative designed to support acute hospitals in England to deliver evidencebased care for older people with frailty. We report on 3 years' experience of whole-systems quality improvement through the network. Using local case studies, we illustrate initiatives through which AFN hospitals improved services and outcomes for older people with frailty and urgent care needs. We describe returns on investment and sustainability of implementation, and reflect on future directions for the AFN.
\end{abstract}

Keywords Frailty $\cdot$ Hospitalisation $\cdot$ Quality improvement $\cdot$ Acute care $\cdot$ Breakthrough series collaborative

\section{Introduction}

\section{The impact of acute hospital admission for older people living with frailty}

Europe has a growing proportion of adults aged over 65, and consequently a growing number of people with frailty

James David van Oppen

jvo3@leicester.ac.uk

Simon Conroy

spc3@leicester.ac.uk

1 University of Leicester, Leicester, UK

2 Acute Frailty Network, London, UK

3 King's College London, London, UK
[1-3]. Frailty is defined as the loss of physiological or metabolic reserves $[4,5]$ and characterised by the accumulation of comorbid illnesses or functional deficits [6], causing an increased vulnerability to adverse outcomes in response to acute stressors.

Older people who attend an emergency department (ED) are more likely than younger people to be admitted to hospital [7]. In many European countries, medical patients who do not require high dependency care are admitted from emergency departments to acute medical units for the next stage of their management, from where they may either be discharged or transferred to a specialty ward for ongoing care (Fig. 1). In some hospitals there are specialty wards for those medical patients who are frail or over a specific age, while elsewhere patients of all ages are accommodated together. 
Fig. 1 The acute care chain: process to acute admission (example)

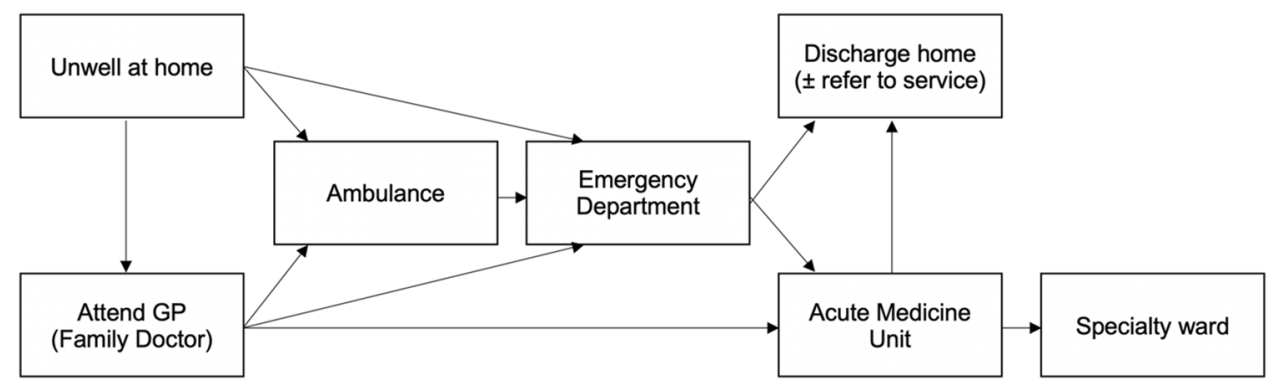

Around one-third of patients in acute medical units are older people with frailty [8], who are at risk of functional decline and a period of intensive health and social care service use [9], such as prolonged length of stay, 30-day mortality, and 30-day readmissions [10]. Early-risk stratification is important to allow frailty-attuned interventions to be delivered earlier in the admission.

Around one-third of patients in UK acute medical units are older people with frailty [8], for whom admission can be associated with functional decline and a period of intensive health and social care service use [9]. These patients have higher resource use and a high risk of adverse outcomes including prolonged length of stay, 30-day mortality, and 30-day readmissions [10]. Early identification during an inpatient episode of patients who have frailty is important for clinical decisions about aims of care to be facilitated and interventions to be frailty-attuned earlier in the admission.

\section{Initiatives in acute frailty care}

Government and health policy leaders, and many clinicians, regard existing models of acute hospital care to be unsuitable and probably unsustainable. For example, in England an annual deficit of 6.2 million bed-days is predicted for 2022 [11]. Acute services require appropriate processes to deliver optimal acute management and reduce reliance on inpatient care, as although major efforts are underway to curtail hospital use, acute crises will always occur. Policy and guidance documents, such as The Silver Book [12], have placed emphasis on expanding day-care initiatives and improving cohesion between departments in hospitals and the community to shorten admissions [11, 13].

In England, the NHS promotes service innovation and improvement through a range of "arms' length" bodies. The Acute Frailty Network (AFN) was initiated by one such body, NHS Elect (https://www.nhselect.nhs.uk), a national members' network organisation providing high-quality support and training to NHS organisations. The AFN aims to improve system resilience and support the adoption, provision and sharing of best practice in urgent care for older people with frailty. The focus is the first $72 \mathrm{~h}$ following acute hospital attendance, with an emphasis on early discharge supported by the wider health and social care system.

\section{Objective of the present paper}

This paper describes the formation and approach of the AFN, and uses local case studies to illustrate the early impact of the Network. Reflections on 3 years' experience of planning and implementing a whole-systems quality improvement collaborative are shared.

\section{Methods}

\section{The AFN's approach to whole-systems quality improvement}

The AFN was designed using the Breakthrough Series Collaborative (BTS) approach [14], supported by national stakeholders: NHS England (the overall governing body), the British Geriatrics Society, the Royal College of Emergency Medicine, Society for Acute Medicine and the Royal College of Nursing. This quality improvement method adopts the Model for Improvement [15] and focuses on introducing and refining change through Plan-Do-StudyAct cycles, with the aim to improve local services by involving wider health and social care systems with support from national clinical and improvement experts.

The AFN supports hospitals in reconfiguring and redesigning services in accordance with its guiding principles (Table 1), encompassing the early identification of older people with frailty to trigger a prompt and evidence-based multi-disciplinary assessment and response. Given that the evidence base supports CGA being more effective than usual acute care for older people [16-18], the AFN supports hospitals to optimise their delivery of CGA in urgent care settings, which previously had been variably offered in the acute phase by NHS hospitals [19]. 
Table 1 The core AFN principles (https://www.acute frailtynetwork.org.uk)
1. Establish a mechanism for early identification of people with frailty

2. Put in place a multi-disciplinary response that initiates comprehensive geriatric assessment (CGA) within the first hour

3. Set up a rapid response system for frail older people in urgent care settings

4. Adopt clinical professional standards to reduce unnecessary variation

5. Develop a measurement mind-set

6. Strengthen links with services both inside and outside hospital

7. Put in place appropriate education and training for key staff

8. Identify clinical change champions

9. Patient and public involvement

10. Identify an executive sponsor and underpin with a robust project management structure
The Health Foundation has recently described [20] the challenge of "replicability" within service development programmes. They reflected that a new intervention's successful uptake, with replication of impact as well as form, requires adaptation and implementation to local settings. The AFN fundamentally recognises the need for distributed and collaborative effort in improving outcomes for older people, encouraging and fostering an implementation ethos among participating hospital teams. Over 3 years, five cohorts totalling around 70 hospital sites have been AFN participants.

\section{Support offered to participating hospitals}

Each hospital team participating in the AFN is allocated a "coach" and has access to quality improvement, measurement and clinical expertise to support planning, delivery, and monitoring of local change and service redesign. The 12 month programme begins with a "diagnostic walkthrough" of the service from the ED to the wards, guided by the local clinical and managerial team. This provides an understanding of the local context, plans for change and possible barriers. This emergent understanding is fed back to sites with recommendations for improvements. At this initial meeting, the participants complete a "Sustainability Assessment" exercise to provide insights into their various perceptions of local factors relevant to successfully implementing and sustaining the planned changes. During the programme, teams from participating hospitals attend four national events and a series of masterclasses and webinars to support team development, networking, and sharing of experiences. They have access to the AFN's Toolkit-an iteratively developed package which contains service improvement principles, specific measurement support, and bespoke Experience-Based Design (EBD) aids [21].

The AFN coaches teams to use EBD as an approach to involve patients and the public as co-designers within their improvement teams. This tool, specially adapted by the AFN for use with frail older people, captures the experiences of those who use and deliver frailty services to put the patient perspective at the centre of subsequent pathway improvements. Staff work together with patients and carers to gather data to understand experiences in the service and then engage with patient groups to co-design improvements that will make patients' experience in the service improve.

A shared vision and collective understanding of "the way we do things around here" is inspired, to enable coordination of individuals with different backgrounds and perspectives to provide multidisciplinary attention to the outcomes that are important to patients. The AFN encourages values and standards for person-centred patient care to be written and driven by clinical leaders to reduce unnecessary variation and instil best practice. This approach is not limited to the hospital environment; to support ongoing care and resettlement following an admission, a core AFN principle is for sites to strengthen links between their urgent care services and community teams, including primary care services and third-sector agencies such as the Red Cross and Age UK.

Establishing successful frailty services requires the testing and implementation of many changes, involving many health and social care professionals and crossing organisational barriers. Critical to the AFN's approach is the ongoing support of clinical and implementation experts throughout intervention cycles, to guide improvement and to identify unexpected consequences for patients and services. Site visits from measurement experts and access to the NHS Elect Measurement for Improvement Guide [22] give hospital teams the ability to obtain and effectively use data, some examples of which are shared in the following case studies.

\section{Results}

\section{Case study 1: site ' $\mathrm{N}^{\prime}$}

At site ' $\mathrm{N}$ ', no patients were consistently receiving CGA within $72 \mathrm{~h}$ from admission. The hospital's Acute Frailty Improvement Team (with their Chief Operating Officer as 
Fig. 2 Number of older patients at site ' $\mathrm{N}$ ' whose hospital admission exceeded 14 days. The trend towards fewer prolonged admissions may represent earlier hospital discharges as a result of frailty-attuned interventions

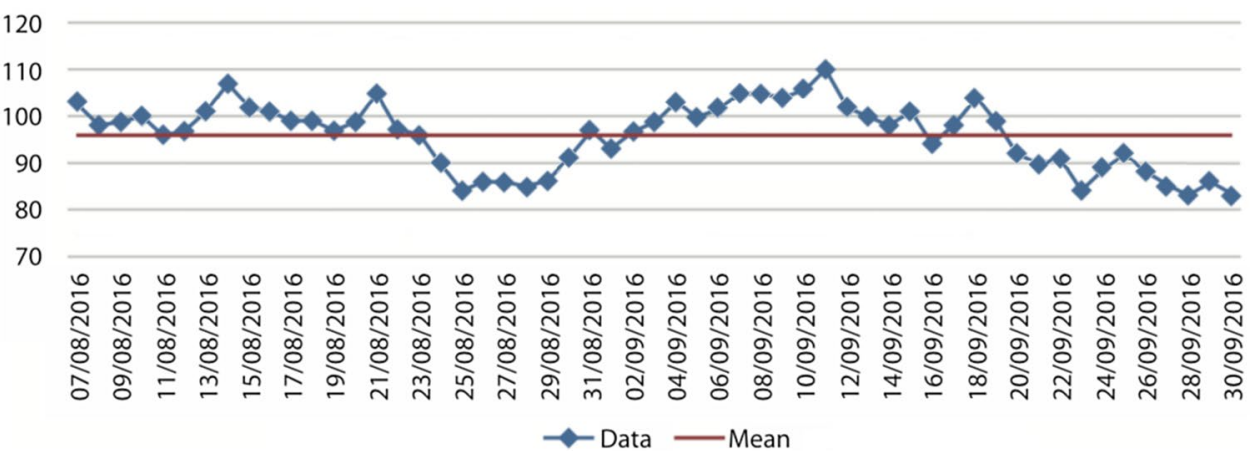

executive sponsor) engaged and involved each specialty to change culture and agree unanimously that "frailty is everyone's business." The team introduced and iteratively improved a simple screening tool which enabled admissions staff to easily and rapidly identify people who potentially had frailty. These patients then received a more in-depth specialist review, and over 1 year $73 \%$ received CGA within $72 \mathrm{~h}$. During this period, the team identified an associated decrease in the number of older patients with admissions prolonged over 14 days (Fig. 2). The data are presented as control charts to discern the pattern of change from underlying "common cause" and artefact "special cause" variation [23].

\section{Case study 2: site ' $Q$ '}

Previous initiatives to improve the frailty pathway at the 1400-bed acute Site 'Q' had been anecdotally successful. However, the team lacked clear impact evidence to support their improvement plans and were unable to secure ongoing funding. At the outset of their AFN participation the site audited their service against The Silver Book [12] standards, showing that the majority of patients were not receiving timely CGA. With executive buy-in, the team used experience-based design techniques to understand the experiences of older people in hospital and used their findings as a basis for improvement. Interventions included information leaflets, changes to nutrition routines in ED, improvements to the ward environment, and development of patient experience videos for educational use for key staff. A Frailty and Interface Team was formed to provide a 12-hour daily service of geriatricians, nurses, allied health professionals and social workers, who together provided an enhanced "front door" response early in the patient journey (Fig. 3). An in-depth review of the service evidenced savings linked to its frailty improvement work of over £1.3million.

\section{Case study 3: site 'B'}

A similar return on investment was demonstrated by Site 'B'. During their AFN participation, the team designated a ward for patients with frailty and allocated a geriatrician, social worker, pharmacist, and therapy team. The team worked together to develop links outside of the hospital, purchasing interim beds in local care homes to enable those patients awaiting care packages to receive assessments in the community rather than as inpatients. By improving the efficiency
Fig. 3 Number of older patients at site 'Q' for whom admissions were avoided: a front-door intervention team discharged more patients from the ED, reducing the rate of conversion to hospital admission. In the same time period, ED attendances and 30-day reattendances remained stable

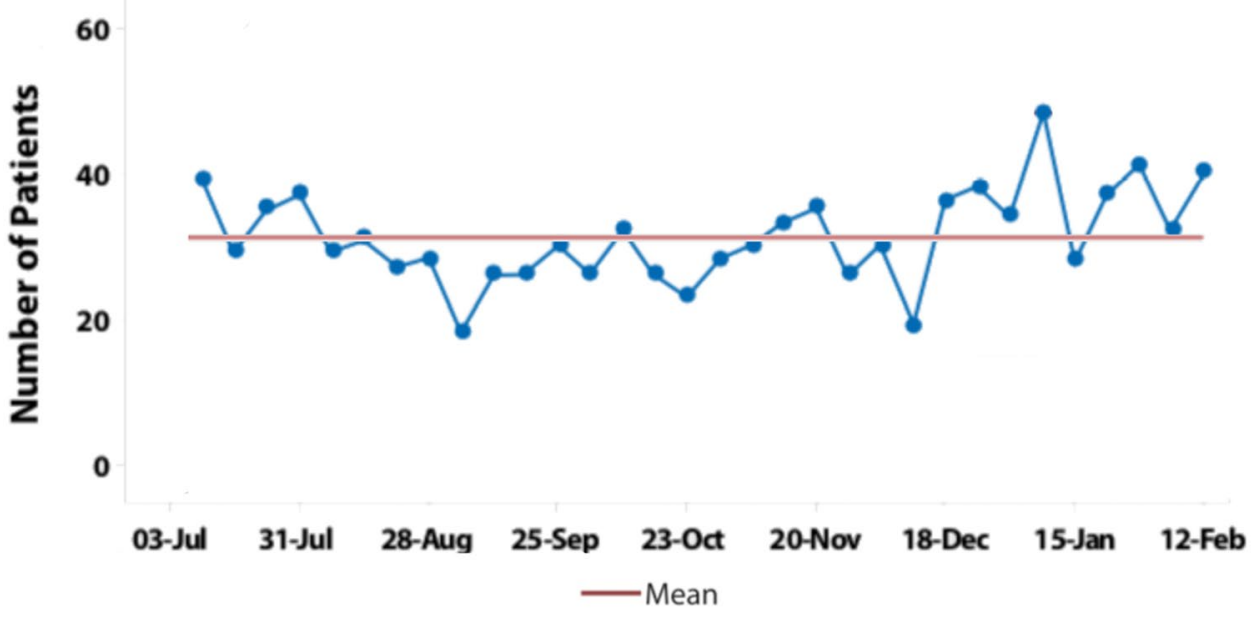




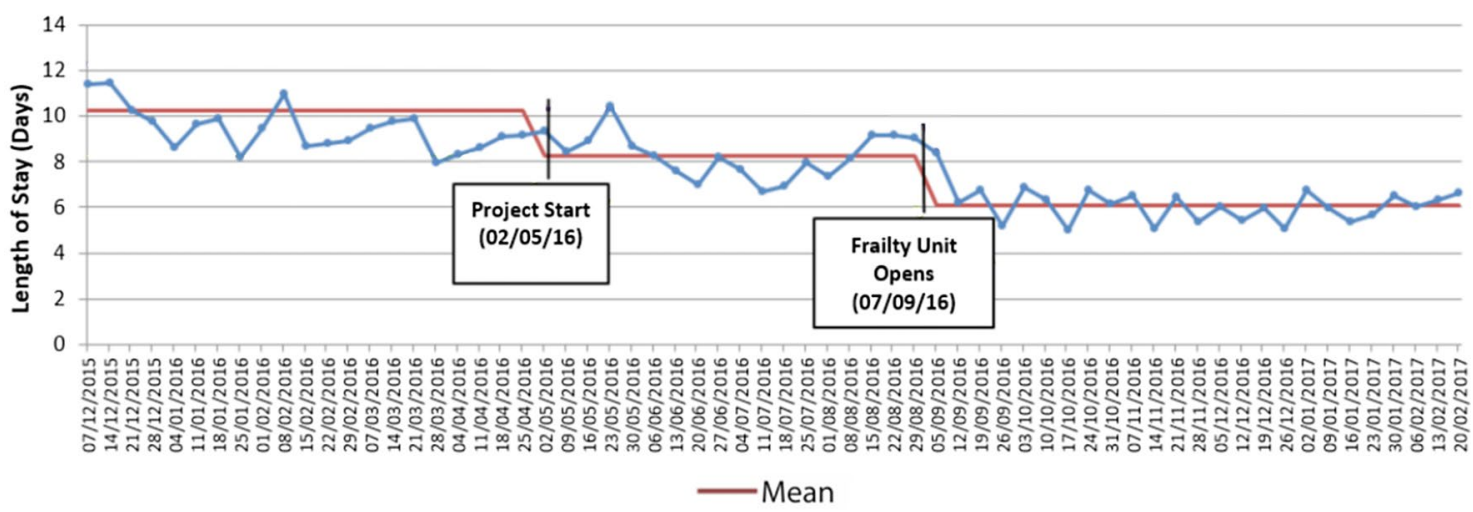

Fig. 4 Average length of stay for older patients with frailty at site ' $\mathrm{B}$ '

Table 2 Domains of the NHS sustainability model and guide [24]

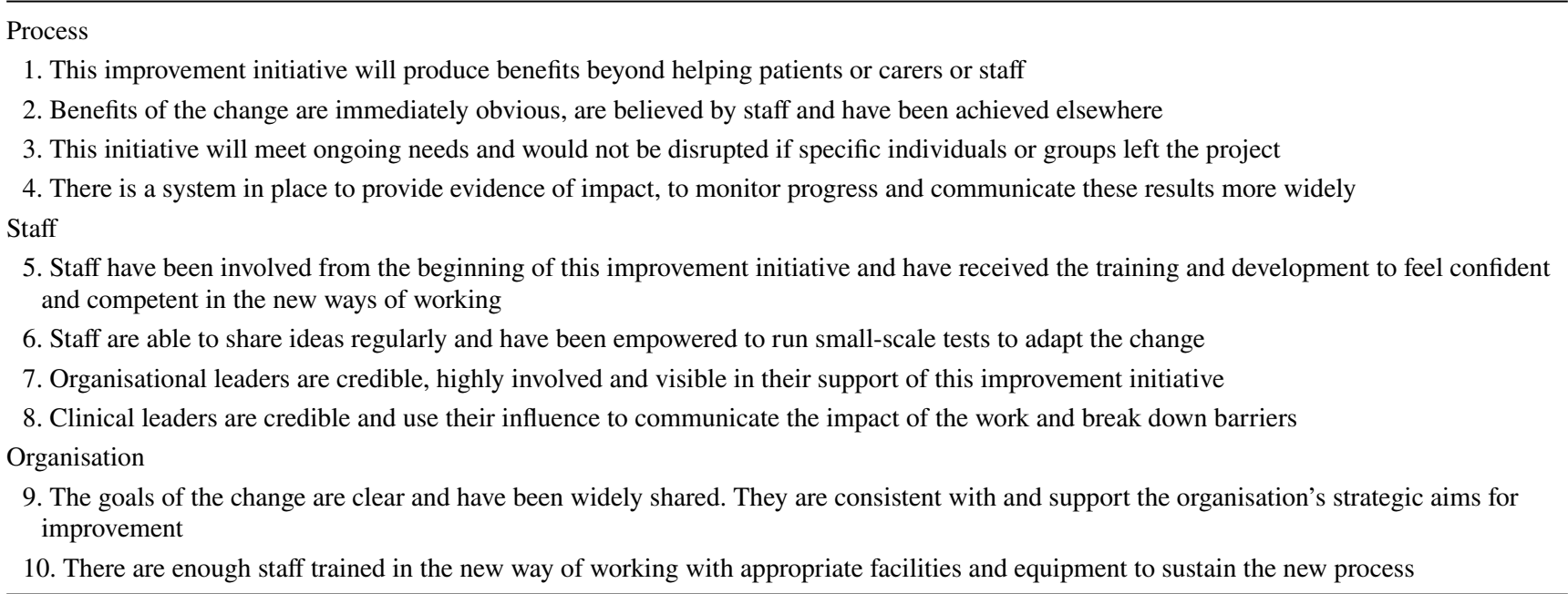

of care transitions during the discharge process, the team improved patient flow and reduced the rate of patients being cared for on non-geriatric wards. This allowed more clinical focus for frail older people who occupied the correct specialty beds. Mean length of stay reduced by four days (Fig. 4), resulting in an annual cost reduction of $£ 3.2$ million.

\section{Sustainability}

There are literature reports of high rates of failure among quality improvement initiatives. Since inception, the AFN has applied the NHS Sustainability Model [24] as a method to measure and improve the degree to which improvements are integrated into routine practice. The model is a diagnostic tool that helps identify strengths and weaknesses in implementation plans, collating team members' selfassessment scores across ten domains of processes, staff and organisation (Table 2). Used early during AFN participation, it predicts the likelihood of improvements being sustained.
The tool has been most effectively used when teams engaged directly with the assessment process during initial site visits with network coaches, rather than via paper or electronic questionnaires.

Aggregated sustainability data at a programme level are also used to inform design of the learning collaborative and processes are developed to support sites and strengthen any identified weaknesses. For example, senior leadership has been identified as a weakness and with this in mind the AFN team now meet with the participating sites' executives and provide regular updates for them to strengthen their involvement and engagement in the local project. The sustainability assessment is repeated again in the last phase of the project and the AFN has observed improvement in individual sites' sustainability scores during their participation. Using this tool has allowed hospital teams to recognise weaknesses and so strengthen their infrastructure and leadership to make their projects successful. 


\section{Discussion}

We have highlighted some of the approaches used to achieve high-quality care for older people with frailty, describing how the AFN has set about delivering improvement on a large scale. While there is limited evidence for collaborative quality-improvement initiatives [25, 26], the individual AFN principles (including early identification of frailty and early CGA) are evidence-based. We have used case studies to illustrate local improvement of outcomes and return on investment, but also to demonstrate the importance of robust measurement. Our next step is evaluation of the AFN's impact as a whole network, to either prove an indication for ongoing intervention or to inform redesigned approaches.

We are not aware of any similar initiatives focusing upon acute care for older people in other parts of Europe, although there are early discussions taking place in the Netherlands. However, all European countries will be facing similar issues, so we hope that this brief report might provide some stimulus to develop similar approaches aimed at improving outcomes for frail older people with acute care needs. There is a European Geriatric Emergency Medicine Special Interest Group (GEM SIG-https://geriemeurope.eu/) which brings together the European Union Geriatric Medicine Society (EUGMS) and the European Union Society for Emergency Medicine (EUSEM). The GEM SIG's mission is to develop sustainable clinically and cost-effective patientcentred health care systems that improve relevant outcomes for older patients in Emergency Medicine across Europe [27].

Acknowledgements JvO holds a National Institute for Health Research Academic Clinical Fellowship.

\section{Compliance with ethical standards}

Conflict of interest DT, MT, SG, FM, and SC have leadership appointments in the Acute Frailty Network. FM is the current president of the EUGMS

Ethical approval This article does not contain any studies with human participants or animals performed by any of the authors.

Informed consent For this type of study, formal consent was not required.

Open Access This article is distributed under the terms of the Creative Commons Attribution 4.0 International License (http://creativeco mmons.org/licenses/by/4.0/), which permits unrestricted use, distribution, and reproduction in any medium, provided you give appropriate credit to the original author(s) and the source, provide a link to the Creative Commons license, and indicate if changes were made.

\section{References}

1. Kingston A, Comas-Herrera A, Jagger C (2018) Forecasting the care needs of the older population in England over the next 20 years: estimates from the Population Ageing and Care Simulation (PACSim) modelling study. Lancet Public Health 3(9):e447-e455

2. Rechel B, Grundy E, Robine JM, Cylus J, Mackenbach JP, Knai C et al (2013) Ageing in the European Union. Lancet 381(9874):1312-1322

3. Spillman BC, Lubitz J (2000) The effect of longevity on spending for acute and long-term care. N Engl J Med 342(19):1409-1415

4. Fried LP, Tangen CM, Walston J, Newman AB, Hirsch C, Gottdiener J et al (2001) Frailty in older adults: evidence for a phenotype. J Gerontol Ser A Biol Sci Med Sci 56(3):M146-M156

5. Chen X, Mao G, Leng SX (2014) Frailty syndrome: an overview. Clin Interv Aging 9:433-441

6. Rockwood K, Mitnitski A (2011) Frailty defined by deficit accumulation and geriatric medicine defined by frailty. Clin Geriatr Med 27(1):17-26

7. Blunt I, Bardsley M, Dixon J (1999) Trends in emergency admissions in England 2004-2009: is greater efficiency breeding inefficiency? Nuffield Trust, London

8. Conroy S, Dowsing T (2013) The ability of frailty to predict outcomes in older people attending an acute medical unit. Acute Med 12(2):74-76

9. Krumholz HM (2013) Post-hospital syndrome - an acquired, transient condition of generalized risk. N Engl J Med 368(2):100-102

10. Gilbert T, Neuburger J, Kraindler J, Keeble E, Smith P, Ariti C et al (2018) Development and validation of a Hospital Frailty Risk Score focusing on older people in acute care settings using electronic hospital records: an observational study. Lancet 391(10132):(10132):1775-1782

11. Smith P, McKeon A, Blunt I, Edwards N (2014) NHS hospitals under pressure: trends in acute activity up to 2022 . Nuffield Trust, London

12. Banerjee J, Conroy S (2012) The Silver Book: quality care for older people with urgent and emergency care needs. London. https ://www.bgs.org.uk/resources/silver-book. Accessed 18 Nov 2018

13. NHS England (2014) Safe, compassionate care for frail older people using an integrated care pathway: practical guidance for commissioners, providers and nursing, medical and allied health professional leaders. London. https://www.england.nhs.uk/wpcontent/uploads/2014/02/safe-comp-care.pdf. Accessed 23 Oct 2018

14. Institute for Healthcare Improvement (2003) The Breakthrough series: IHI's collaborative model for achieving breakthrough improvement. Institute for Healthcare Improvement, Boston

15. G Langley R Moen K Nolan T Nolan C Norman L Provost 2009 The improvement guide: a practical approach to enhancing organizational performance 2 Jossey-Bass Publishers San Francisco

16. Ellis G, Whitehead M, O'Neill D, Robinson D, Langhorne P (2011) Comprehensive geriatric assessment for older adults admitted to hospital. Cochrane Database Syst Rev 6(7):CD006211

17. Fox MT, Persaud M, Maimets I, O'Brien K, Brooks D, Tregunno D et al (2017) 2237-2245

18. Baztan JJ, Suarez-Garcia FM, Lopez-Arrieta J, Rodriguez-Manas L, Rodriguez-Artalejo F (2009) Effectiveness of acute geriatric units on functional decline, living at home, and case fatality among older patients admitted to hospital for acute medical disorders: meta-analysis. BMJ 338(jan22_2):b50

19. NHS Benchmarking Network (2015) Older people in acute settings benchmarking report. London. https://www.nhsbenchma rking.nhs.uk/news/older-people-in-acute-settings-benchmarki ng-report. Accessed 18 Nov 2018 
20. Horton T, Illingworth J, Warburton W (2018) The spread challenge: how to support the successful uptake of innovations and improvements in health care. The Health Foundation, London

21. NHS Institute for Innovation and Improvement (2009) Experience based design: using patient and staff experience to design better healthcare services. https://improvement.nhs.uk/resources/ the-experience-based-design-approach/. Accessed 25 Nov 2018

22. Davidge M, Holmes M, Shaw A, Shouls S, Tite M (2015) Guide to measurement for improvement: NHS Elect. https://www.nhsel ect.nhs.uk/uploads/files/1/Resource/Service\%20Transformatio n\%202016/NHS\%20Elect-Measurement\%20for\%20Improvem ent-Feb17.pdf. Accessed 18 Nov 2018

23. Mohammed M (2004) Using statistical process control to improve the quality of health care. BMJ Qual Saf 13:243-245

24. Maher L, Gustafson D, Evans A (2010) NHS sustainability model. NHS Institute for Innovation and Improvement. https://webar chive.nationalarchives.gov.uk/20160805122935/http://www. nhsiq.nhs.uk/media/2757778/nhs_sustainability_model_-_febru ary_2010_1_.pdf. Accessed 18 Nov 2018

25. Nadeem E, Olin SS, Hill LC, Hoagwood KE, Horwitz SM (2013) Understanding the components of quality improvement collaboratives: a systematic literature review. Milbank Q 91(2):354-394

26. Wells S, Tamir O, Gray J, Naidoo D, Bekhit M, Goldmann D (2018) Are quality improvement collaboratives effective? A systematic review. BMJ Qual Saf 27(3):226-240

27. EUGMS (2018) European Task Force on Geriatric Emergency Medicine (ETGEM). https://eusem.org/sections-and-committees /geriatric-section/gemtaskforce. Accessed 19 Jan 2019

Publisher's Note Springer Nature remains neutral with regard to jurisdictional claims in published maps and institutional affiliations. 